\title{
Idiopathic granulomatous mastitis and steroid use during the pandemic of COVID-19
}

\author{
Hasan Calis*, Zulfikar Karabulut, Yilmaz Guler and Serkan Sengul \\ Department of General Surgery, Faculty of Medicine, Alanya Alaaddin Keykubat University, Alanya, Turkey
}

\begin{abstract}
.
BACKGROUND: Steroid therapy is an immunosuppressive treatment and may have possible side effects in a pandemic period. However, the number of studies on the use corticosteroids for the treatment of idiopathic Granulomatous Mastitis (IGM) especially during the pandemic is almost negligible.

METHODS: The data of patients with the diagnosis of IGM between January-December 2020 in the General Surgery Clinic were retrospectively analyzed. The patients were explained in detail that steroid therapy is an immunosuppressive treatment and it may have possible side effects. Prednisolone $0.5-1 \mathrm{mg} / \mathrm{kg} /$ day was given as steroid therapy. The treatment was planned for $4-6$ months according to the severity of the symptoms and was completed by reducing it to a total dose of $10 \mathrm{mg} / \mathrm{month}$.

RESULTS: Eleven patients were included in the study. Five patients had completed steroid treatment and continued their followup. In our study, a total of six patients were receiving steroid therapy.

CONCLUSIONS: There is no consensus yet on the use of the steroid in the COVID-19 pandemic. Low doses Corticosteroids $(<1 \mathrm{mg} / \mathrm{kg} /$ day $)$ don't have an effect on increase mortality in patients with severe COVID-19. We can think that low-dose corticosteroids used by many centers in IGM treatment do not have a negative effect on mortality.
\end{abstract}

Keywords: Idiopathic granulomatous mastitis, steroid treatment, COVID-19 pandemic, immunosuppressive

\section{Introduction}

In December 2019, a group of atypical pneumonia cases started to appear in Wuhan, China. The pathogen responsible for this was a new type of coronavirus and it was named Severe Acute Respiratory Syndrome Coronavirus-2 (SARS-CoV-2). This pathogen spread throughout the world [1]. Since then, the whole world has been struggling with this disease, which has been called the COVID-19 pandemic, and various treatment methods are still administered. Initially, the World Health Organization recommended not to use corticosteroids in the treatment of COVID-19. The reason for this was that, in the past, administration of corticosteroids to SARS patients did not have a significant beneficial effect on survival, and it was known that possible

\footnotetext{
${ }^{*}$ Corresponding author: Hasan Calis, Department of General Surgery, Faculty of Medicine, Alanya Alaaddin Keykubat University, 07400, Alanya, Turkey. Tel.: +90 5055361380; E-mail: drhasancalis@hotmail.com.

ORCIDs: https://orcid.org/0000-0003-4182-798X (H. Calis); http://orcid.org/0000-0002-9394-8233 (Z. Karabulut): http://orcid.org/0000-0002-3225-6348 (Y. Guler); http://orcid.org/0000-0003-4691-5663 (S. Sengul).
}

adverse events related to corticosteroids such as avascular necrosis, psychosis, diabetes and delayed viral clearance may develop [2]. However, with the resumption of corticosteroids in the treatment of the COVID-19, it was seen that corticosteroids had a positive effect on mortality in COVID-19 patients, and interest in this treatment started to increase again. Recommendations following the published data on this issue included the use of steroids in patients with COVID-19 and acute respiratory distress syndrome (ARDS) as a weak suggestion. As a result, with these vague and timeconsuming recommendations, the regular use of corticosteroids in COVID-19 patients has been accepted as a common view [3,4]. In our hospital, corticosteroid therapy is used in the standard treatment of patients with COVID-19.

IGM (Idiopathic Granulomatous Mastitis) is a rare, chronic, non-malignant and non-life-threatening breast disease [5]. It has similar clinical and radiological features with other granulomatous diseases and breast cancers. There is no standard algorithm of diagnosis and treatment for IGM in the current literature. Corticosteroids are among the most common and oldest methods of treatment. There is a general consensus that 
antibiotherapy should be started as initial therapy in patients presenting with findings of abscess and cellulite. However, antibiotics are not given to any patient with a breast mass and no signs or symptoms of mastitis [6]. Numerous studies have been published recently regarding IGM therapy. Yet, there is a significant heterogeneity in these studies. We are fully aware that steroid therapy is an immunosuppressive treatment and may have possible side effects, especially since we are in a pandemic period. However, the number of studies on the use corticosteroids for the treatment of IGM especially during the pandemic is almost negligible.

In this study, we aimed to retrospectively evaluate whether IGM patients who were followed up and treated before and during the pandemic showed variability in both surgical and steroid treatments, and their compliance with treatment, especially during the pandemic.

\section{Methodology}

The data of patients aged 18 years and older who were treated with the diagnosis of idiopathic granulomatous mastitis between January 2020 and December 2020 in the General Surgery Clinic of Alanya Alaaddin Keykubat University Training and Research Hospital were retrospectively analyzed. Follow-up information including demographic characteristics, surgery histories, diagnosis and treatment methods, follow-ups and treatment times of all cases were recorded.

Since the surgeons participating in the study acknowledge that IGM is an autoimmune pathology, medical treatment was applied first unless there is a condition that requires surgery such as abscess or necrosis. In medical treatment, corticosteroid therapy was given first. Since we are in a pandemic, the patients were explained in detail that steroid therapy is an immunosuppressive treatment and it may have possible side effects. Prednisolone 40-60 mg/day was given as steroid therapy. The treatment was planned for 4-6 months according to the severity of the symptoms and was completed by reducing it to a total dose of 10 $\mathrm{mg} / \mathrm{month}$. Surgical treatment was preferred primarily in patients who did not respond to medical treatment or who had pathologies such as abscess and necrosis. After obtaining the consents of the patients, the treatment method was determined together.

Patients with other known granulomatous pathology and immune system disease were excluded from the study. The following and staining methods were performed on the tissue samples and aspiration materials obtained from the patients; Hematoxylin + eosin (H \& E) staining for histopathological investigation, alkaline-acid resistance factors for tuberculosis bacteria (AARB) and Lowenstein-Jensen culture, polymerase chain reaction on tissues (PCR) Ehrlich ZiehlNeelsen (EZN) staining and Periodic acid-Schiff (PAS) staining for the investigation of fungal infection.

The demographic data of the patients and the data related to diagnosis-treatment and postoperative period follow-up were recorded, and descriptive statistics were analyzed using Microsoft Excel 2016.

\section{Results}

Eleven patients were included in the study. Eight of them were patients who had been diagnosed with IGM before, and the rest were patients who were diagnosed as of March 2020. Of the eight patients who were diagnosed before the pandemic, five had completed steroid treatment and continued their follow-up, and three were still on steroid therapy. In our study, a total of six patients were receiving steroid therapy.

The first of three patients who were diagnosed with IGM after March 2020 was diagnosed in the postpartum 4th month and she had a history of lactation. This patient had an ulcerated lesion with purulent discharge $2 \mathrm{~cm}$ from the areola at the 3 o'clock position of the right breast and an erythematous lesion $1 \mathrm{~cm}$ from the areola at the 7 o'clock position of the left breast. She was referred to our clinic with a pre-diagnosis of IGM after abscess drainage in another center. A core biopsy was performed for diagnosis. There was no growth in the wound culture. Steroid therapy at a dose of 60 $\mathrm{mg} /$ day and anti-inflammatory therapy was initiated. During her follow-up, the patient did not continue the drug as she wanted to stop taking it due to the immunosuppressive effect of the steroid. At the second month follow-up of the patient, abscess developed at the lesion location in the right breast. The lesion was drained and a sample was taken. Steroid treatment was restarted. The patient stopped taking her steroid again one month later and refused the treatment. She is currently being followed up without steroid therapy and whenever abscess develops, it is drained. Our other patient had abscess drainage 6 months ago in another center at the 2 o'clock position of the left breast. Core biopsy was performed on the patient who had recurrent discharge. There was no growth in the wound culture and the patient was 
diagnosed with IGM. Steroid therapy was initiated. She stopped her treatment in the 4 th month because she could not come for control due to the pandemic. In the 6th month of follow up, the patient was admitted with abscess in the same area; the abscess was drained and steroid therapy was started. The patient is still being followed up and treated. The third patient presented with recurrent erythema and ulcerated wounds at the 6 o'clock position of the right breast and was diagnosed with IGM with core biopsy. Steroid treatment at a dose of $60 \mathrm{mg}$ /day continues in the $3 \mathrm{rd}$ month of her follow up.

No patients in the study had COVID-19 infection.

None of the patients had any significant side effects of steroid treatment except weight gain, change in facial appearance, neck thickening and skin lines. The characteristic features of the patients are shown in Table 1.

\section{Discussion}

Idiopathic Granulomatous Mastitis (IGM) is a rare, chronic, non-malignant and non-life threatening breast disease. It may be exhibit similar clinical and radiological features with other granulomatous diseases and breast carcinomas [7]. It was first described in 1972 and its etiology remains unclear $[5,8]$. There is no common consensus on the treatment protocol of IGM. While surgical treatments were used more frequently in the past, alternative treatment methods were tried afterwards, and even follow-up method on its own has been recommended among treatment methods [8,9]. Furthermore, there are studies that suggest surgical methods including mastectomy. However, especially in most of the recent studies, it is recommended that non-surgical treatments should be the first choice of treatment for these patients since repetition of surgical procedures may lead to cosmetic breast problems. The first nonsurgical treatment to be used can involve steroid therapy, mostly in patients with severe symptoms. Various immunosuppression treatments or surgical treatments may be recommended in patients with more severe symptoms or highly recurrent IGM [10,11]. Antibiotherapy is not recommended if there is no growth in the patient's culture $[12,13]$. Some surgeons who have used MTX in the treatment of IGM recommend that the first-line therapy of IGM should always begin with steroid therapy [g2]. However, they recommend the administration of MTX occasionally azathioprine in patients who develop complications (such as glucose intolerance, hypertension, central obesity, and osteoporosis) due to steroid therapy, in patients with poor response to steroid therapy, or in patients who develop remission due to steroid therapy but develop recurrence after discontinuation of steroid therapy. However, MTX can be initiated as a first-line therapy in patients with contraindications that use steroid therapy, but MTX therapy should be initiated at a dose of $5 \mathrm{mg} /$ week and the side effect of the drug should be checked by routine blood tests. Briefly, only a few researchers suggest the use of MTX or MTX plus steroid as the first-line therapy; however, there is a consensus on the use of steroid therapy before initiating MTX [14]. Long-term therapy of MTX and steroids for completely benign disease should be evaluated carefully due to its detrimental effects in patients with an age range of $20-40$ years. Besides nearly $29-50 \%$ recurrence rates following steroids or MTX treatment result in questioning the necessity of steroids or MTX therapy in patients. Therefore, one of the radical surgical treatment options (partial or total mastectomy-plus breast reconstruction) should be offered to reproductive agedpatients who have recurred IGM disease despite more than 2 cycles of steroid and MTX treatment. Since it is necessary to inform the patients correctly about the side effects of long-term immunosuppressive treatment protocols [15].

Since steroid therapy is an immunosuppressive treatment and may have potential side effects, both IGM patients and the treating team have reservations about its use during the pandemic. Regarding this, the number of studies on IGM and use of corticosteroids in the treatment, especially during the pandemic, is almost negligible. However, there are various studies that suggest and do not recommend the use of steroids in the treatment of other diseases requiring immunosuppression during the pandemic. In addition to the studies reporting that steroids used in the period of Middle East respiratory syndrome, which is one of the previous outbreaks, lead to the progression of the disease, studies [16] have also been published, reporting that it will be beneficial to use steroids to prevent hyperinflammation in such diseases [17]. Although the use of steroids was shown to be beneficial in a large number of patients in a different study, it was suggested that this treatment should only be used in clinical research for COVID19 patients. Therefore, there is no consensus yet on the use of the steroid as an immunosuppressive treatment in the COVID-19 pandemic [18]. In a study comparing the efficacy of steroid and other immunosuppressive treatments in patients diagnosed with autoimmune and 
Table 1

Characteristics of patients

\begin{tabular}{|c|c|c|c|c|c|c|c|c|c|}
\hline Patients & $\begin{array}{c}\text { Age } \\
\text { (years) }\end{array}$ & Gender & $\begin{array}{l}\text { Time } \\
\text { (month) }\end{array}$ & $\begin{array}{c}\text { Before } \\
\text { operation }\end{array}$ & Macroscopy & $\begin{array}{l}\text { Diagnostic } \\
\text { method }\end{array}$ & $\begin{array}{l}\text { Frist } \\
\text { treatment }\end{array}$ & Recurrence & $\begin{array}{l}\text { Second } \\
\text { treatment }\end{array}$ \\
\hline 1 & 38 & Female & 10 & No & $\begin{array}{l}\text { Erythema on } \\
\text { the right breast }\end{array}$ & Core biopsy & $\begin{array}{l}\text { Steroid } \\
\text { treatment }\end{array}$ & Yes & $\begin{array}{c}\text { Abscess } \\
\text { drainage, steroid } \\
\text { treatment }\end{array}$ \\
\hline 2 & 34 & Female & 7 & $\begin{array}{l}\text { Abscess } \\
\text { drainage }\end{array}$ & $\begin{array}{l}\text { Bilateral breast } \\
\text { discharge }\end{array}$ & $\begin{array}{l}\text { Abscess drainage } \\
\text { and incisional } \\
\text { biopsy }\end{array}$ & $\begin{array}{l}\text { Steroid } \\
\text { treatment }\end{array}$ & No & Follow \\
\hline 3 & 41 & Female & 10 & No & $\begin{array}{l}\text { Bilateral breast } \\
\text { discharge }\end{array}$ & Core biopsy & $\begin{array}{l}\text { Steroid } \\
\text { treatment }\end{array}$ & Yes & $\begin{array}{c}\text { Abscess } \\
\text { drainage, steroid } \\
\text { treatment }\end{array}$ \\
\hline 4 & 42 & Female & 5 & No & $\begin{array}{l}\text { Right breast } \\
\text { discharge }\end{array}$ & Core biopsy & $\begin{array}{l}\text { Steroid } \\
\text { treatment }\end{array}$ & No & Follow \\
\hline 5 & 49 & Female & 25 & No & $\begin{array}{c}\text { Mass in the left } \\
\text { breast }\end{array}$ & $\begin{array}{c}\text { Core and } \\
\text { excisional biopsy }\end{array}$ & $\begin{array}{l}\text { Steroid } \\
\text { treatment }\end{array}$ & No & Follow \\
\hline 6 & 43 & Female & 10 & No & $\begin{array}{l}\text { Erythema on } \\
\text { the left breast }\end{array}$ & Core biopsy & $\begin{array}{l}\text { Steroid } \\
\text { treatment }\end{array}$ & No & Follow \\
\hline 7 & 50 & Female & 12 & No & $\begin{array}{l}\text { Right breast } \\
\text { wound }\end{array}$ & Core biopsy & $\begin{array}{l}\text { Steroid } \\
\text { treatment }\end{array}$ & No & Follow \\
\hline 8 & 49 & Female & 10 & No & $\begin{array}{l}\text { Right breast } \\
\text { discharge }\end{array}$ & Core biopsy & $\begin{array}{l}\text { Steroid } \\
\text { treatment }\end{array}$ & No & Follow \\
\hline 9 & 26 & Female & 7 & $\begin{array}{l}\text { Abscess } \\
\text { drainage }\end{array}$ & $\begin{array}{l}\text { Bilateral breast } \\
\text { discharge } \\
\text { (lactation) }\end{array}$ & Core biopsy & $\begin{array}{l}\text { Steroid } \\
\text { treatment }\end{array}$ & Yes & $\begin{array}{l}\text { Abscess } \\
\text { drainage }\end{array}$ \\
\hline 10 & 37 & Female & 3 & No & $\begin{array}{l}\text { Right breast } \\
\text { discharge }\end{array}$ & Core biopsy & $\begin{array}{l}\text { Steroid } \\
\text { treatment }\end{array}$ & No & Follow \\
\hline 11 & 50 & Female & 6 & $\begin{array}{l}\text { Abscess } \\
\text { drainage }\end{array}$ & $\begin{array}{l}\text { Left breast } \\
\text { discharge }\end{array}$ & Core biopsy & $\begin{array}{l}\text { Steroid } \\
\text { treatment }\end{array}$ & Yes & $\begin{array}{c}\text { Abscess } \\
\text { drainage, steroid } \\
\text { treatment }\end{array}$ \\
\hline
\end{tabular}

chronic inflammatory diseases, a similar recommendation was made and it has been stated that immunosuppression with means other than corticosteroids did not pose a serious risk for COVID-19 and these patients should continue to have biological and non-biological immunosuppression, however the steroids should be limited during COVID-19 pandemic [19].

There are also publications reporting that steroid treatment has positive effects on the COVID-19 pandemic. In one of these studies, it has been reported that steroid therapy may be beneficial in reducing the number of intensive care unit admissions during the pandemic period [20]. Apart from this, it has been stated in recent studies that the effect of steroid treatment cannot be evaluated without considering the dose used. Recent data indicate that corticosteroids, which are defined as low doses of $1 \mathrm{mg} / \mathrm{kg} /$ day and less, do not have an effect that will worsen the treatment process and increase mortality in patients with severe COVID19 , and may be associated with the risk of death in high doses [21]. According to these data, we can assume that low-dose corticosteroids used by many centers in IGM treatment do not have a negative effect on mortality.

Before the COVID-19 outbreak, we comfortably preferred corticosteroid treatment by explaining the possible risks to the patients. It is a known fact that corticosteroids are medications that suppress the immune system, and this can create a fear in patients using this treatment during the pandemic period. Accordingly, the preferences of both the patient and the treating team may change during the pandemic period. Although our two patients who were given steroid treatment during the pandemic period ceased their treatment, none of our patients who used steroid treatment had any significant side effects other than weight gain, altered facial appearance, neck thickening and skin lines.

\section{Conclusion}

Although we conservatively use the surgical treatment option in IGM, surgical treatments are more 
preferred, especially during the pandemic, in patients experiencing the stress of the effects of corticosteroids. However, we believe that steroid treatment can be used without any problems by taking the necessary precautions and following the isolation rules.

Although ours is a retrospective, single-center study with small number of cases, we think that it will contribute to the literature regarding IGM and steroid use, especially during the pandemic. While it is not known when the COVID-19 pandemic will end, more precise information will be obtained with further studies.

\section{Ethical approval}

Ethics committee approval was obtained from Alanya Alaaddin Keykubat University, Faculty of Medicine Ethics Committee (NO: 01-23; January 132021)

\section{Patients' consent}

Informed consents have been obtained from all subjects.

\section{Conflict of interest}

Authors declared no conflict of interest.

\section{Authors' contribution}

HC: Data curation, planning the study design, writing original draft preparation, reviewing and editing.

SS: Data collecting, quality control of data and algorithms.

YG: Contributed in statistical data analysis, interpretation, collection and content writing.

ZK: Contributed in data collection and interpretation.

\section{References}

[1] Wang C, Horby PW, Hayden FG, Gao GF, A novel coronavirus outbreak of global health concern, Lancet Lond Engl, 395: 470473, 2020.

[2] Arabi YM, Mandourah Y, Al-Hameed F, Sindi AA, Almekhlafi GA, Hussein MA et al., Corticosteroid therapy for critically III patients with middle east respiratory syndrome, Am J Respir Crit Care Med, 197: 757-767, 2018.
[3] Wu C, Chen X, Cai Y, Xia J, Zhou X, Xu S et al., Risk factors associated with acute respiratory distress syndrome and death in patients with coronavirus disease 2019 pneumonia in Wuhan, China, JAMA Intern Med, 180: 934-943, 2020.

[4] Alhazzani W, Moller MH, Arabi YM, Loeb M, Gong MN, Fan E et al., Surviving sepsis campaign: Guidelines on the management of critically III adults with Coronavirus Disease 2019 (COVID-19), Intensive Care Med, 46: 854-887, 2020.

[5] Kessler E, Wolloch Y, Granulomatous mastitis: A lesion clinically simulating carcinoma, Am J Clin Path, 58: 642-646, 1972.

[6] Akbulut S, Sahin TT, Comment on comparison of the outcome of low dose and high-dose corticosteroid in the treatment of idiopathic granulomatous mastitis, Asian Pac J Cancer Prev, 21: 2177-2178, 2020.

[7] Calis H, Kilitci A, Granulomatous mastitis concurrence with breast cancer, Eur J Breast Health, 14: 58-60, 2018.

[8] Calis H, Karabeyoglu SM, Follow-up of granulomatous mastitis with monitoring versus surgery, Breast Dis, 37: 69-72, 2017.

[9] Bouton ME, Jayaram L, O’Neill PJ, Hsu C, Komenaka LK, Management of idiopathic granulomatous mastitis with observation, Am J Surg, 210: 258-262, 2015.

[10] Neel A, Hello M, Cottereau A, Graveleau J, Faucal PD, Costedoat-Chalumeau $\mathrm{N}$ et al., Long-term outcome in idiopathic granulomatous mastitis: A western multicentre study, QJM, 106(5): 433-441, 2013.

[11] Calis H, Karakoyun R, Aslaner A, Gunduz UR, Arici C, Management of patients with idiopathic granulomatous mastitis: Presentation of 13 Cases, J Breast Health, 10: 30-34, 2014.

[12] Dağ A, Edizsoy A, Challenges in management of idiopathic granulomatous mastitis during the pandemic of COVID-19, Breast J, 27: 87-88, 2021.

[13] Kok KY, Telisinghe PU, Granulomatous mastitis: Presentation, treatment and outcome in 43 patients, Surgeon, 8: 197-201, 2010

[14] Akbulut S, Yilmaz D, Bakir S, Methotrexate in the management of idiopathic granulomatous mastitis: Review of 108 published cases and report of four cases, Breast J, 17: 661-668, 2011.

[15] Akbulut S, Şahin TT, Comment on: "Treatment of idiopathic granulomatous mastitis and factors related with disease recurrence", Turk J Med Sci, 50: 2071-2072, 2020.

[16] Russell CD, Millar JE, Baillie JK, Clinical evidence does not support corticosteroid treatment for 2019-nCoV lung injury, Lancet, 395: 473-475, 2020.

[17] Shakoory B, Carcillo JA, Chatham WW, Amdur RL, Zhao H, Dinarello CA et al., Interleukin-1 receptor blockade is associated with reduced mortality in sepsis patients with features of macrophage activation syndrome: Reanalysis of a prior phase III trial, Crit Care Med, 44: 275-281, 2016.

[18] Nasim S, Kumar S, Azim D, Ashraf Z, Azeem Q, Corticosteroid use for 2019-nCoV infection: A double-edged sword, Infect Control Hosp Epidemiol, 41: 1244-1245, 2020.

[19] Ungaro RC, Agrawal M, Park S, Hirten R, Colombel JF, Twyman K et al., Autoimmune and chronic inflammatory disease patients with COVID-19, ACR Open Rheumatol, 3: 111115, 2021.

[20] Albani F, Fusina F, Granato E, Capotosto C, Ceracchi C, Gargaruti $\mathrm{R}$ et al., Corticosteroid treatment has no effect on hospital mortality in COVID-19 patients, Sci Rep, 11: 1015, 2021.

[21] Li X, Xu S, Yu M, Wang K, Tao Y, Zhou Y et al., Risk factors for severity and mortality in adult COVID-19 inpatients in Wuhan, J Allergy Clin Immunol, 146: 110-118, 2020. 